\title{
Target-Adverse Events and Fear of Cancer Progression, Anxiety, and Depression in Patients with Advanced Non-Small Cell Lung Cancer
}

Chu Chun Yu

National Taiwan University Hospital

Chia Yu Chu

National Taiwan University Hospital

Yeur Hur Lai

School of Nursing, College of Medicine, National Taiwan University Hospital

Jui Chun Chan

Mackay Medical College

Yen Ju Chen

Department of Nursing, Da-Yeh University

Hui Te Hsu

School of Medicine, National Taiwan University

Yun-Hsiang Lee ( $\nabla$ yhlee338@ntu.edu.tw)

School of Nursinf, College of Medicine, National Taiwan University https://orcid.org/0000-0001-7200-7373

Research Article

Keywords: target-adverse events, non-small cell lung cancer, fear of progress, anxiety, depression

Posted Date: June 14th, 2021

DOI: https://doi.org/10.21203/rs.3.rs-545027/v1

License: (c) (i) This work is licensed under a Creative Commons Attribution 4.0 International License. Read Full License 


\section{Abstract}

Objective: To examine the difference in levels of fear of cancer progression (FoP), anxiety, depression between presence/absence of the target-adverse events (AEs); and to examine the differences in incidence rate of AEs and FoP, anxiety, and depression among three generations of EGFR-TKIs therapy (first, gefitinib and erlotinib [G1]; second, afatinib [G2]; third, osimertinib [G3]) in non-small-cell lung cancer (NSCLC) patients.

Methods: A cross-sectional study design. NSCLC patients $(n=128)$ were recruited from a medical center in Taiwan. A set of structured questionnaires assessing AEs, FoP, anxiety and depression.

Results: Parts of AEs, such as photosensitivity, paronychia, and alopecia, exhibited significantly higher levels of FoP, anxiety, and depression. Less patients experienced $A E s$ in the $\mathrm{G} 3$ group than those in the $\mathrm{G} 1$ or $\mathrm{G} 2$ group but still reported experiencing itching, dry skin with grade 3 severity. The incidence rates of mouth/throat sores, and cheilosis/cheilitis in the $\mathrm{G} 2$ group was significantly higher than those in the G1 or G3 group. The incidence rate of FoP, anxiety and depression were $13.8-26.3 \%, 23.8-40.4 \%$ and $16.7-42.1 \%$, respectively.

Conclusions: The priorities of care among three generations of EGFR-TKIs in patients with NSCLC were established. FoP, anxiety and depression were present among different targeted therapies and require further attention.

\section{Background}

Lung cancer is one of the most life-threatening cancers worldwide. In Taiwan, the number of deaths due to lung cancer accounts for $19.22 \%$ ( $n=9,235)$ of all cancer-related deaths $(n=48,037)$ in 2017 [1]. Approximately 50\% of Asian patients with non-small-cell lung cancer (NSCLC) have mutations in epidermal growth factor receptor (EGFR), which are more than what have been accounted for in Caucasian patients (10\% show EGFR mutations) [2]. A previous study that followed-up the use of first generation (gefitinib, erlotinib) EGFR- tyrosine kinase inhibitor (TKI) in patients with late-stage NSCLC in Taiwan for 3 years found that the survival rate significantly increased and mortality significantly decreased with the use of this therapy [3]. However, patients treated with first (gefitinib and erlotinib) and second (afatinib) generation of EGFR TKIs will eventually develop clinical resistance and up to $60 \%$ of these resistance patients have acquired EGFR exon 20 (T790M) mutations [4]. The third generation (osimertinib) of EGFR-TKIs therapy can then be chosen to continuously control the disease with the benefit of achieving improved central neutral system penetration [5-7]. Thus, the three generations of EGFR-TKIs have now become one of the predominant anti-cancer therapies for patients with lung cancer.

However, target-adverse events (AEs) such as skin rash and xerosis/dry skin are associated with EGFR-TKI use [8, 9]. In fact, targeted therapy was stopped in $10 \%$ of the patients who developed such adverse-events [10]. Recent studies have reported that patients treated with osimertinib treatment have better progression-free survival [11] and lower frequency of grade 3 or 4 AEs (rash, pruritus, xerosis/dry skin, and paronychia) than patients treated with gefitinib, erlotinib [11], or afatinib [12]. These target adverse effects were assessed by professionals. To improve the quality of personal, professional, and organizational relationships, patient-center care should also give consideration to patient voice during assessment in clinical settings [13]. Additionally, a review article also pointed out the gaps of patient voice concerning adverse-events from EGFR inhibitors [14]. Thus, the perspectives of both patients and professionals regarding AEs will be simultaneously assessed in this study.

According to the middle-range theory of unpleasant symptoms, physiological and psychological factors can simultaneously influence an individual's health status [15]. There is evidence which indicates that skin toxicity negatively affects patients' emotions, life functioning, and quality of life [9, 16]. Thus, patients with NSCLC receiving targeted therapies, that had AEs (e. g., acneiform eruption/ acne, pruritus/ itching, dry skin/ skin dryness, paronychia, hyperpigmentation, photosensitivity, alopecia/ hair loss, and hypertrichosis, mouth/throat sores, and cheilosis/cheilitis) and fear of cancer progression (FoP), anxiety, and depression were selected as physiological and psychological factors in this study. In relation to physiological factors, previous studies on the differences among different EGFR-TKI therapies focused more on patients treated with gefitinib, erlotinib, and afatinib. However, few studies explored some parts of the adverse events such as acneiform eruption, pruritus, dry skin, paronychia $[9,17]$ and diarrhea $[18,19]$. Furthermore, one study reported that a lower incidence rate of AEs with grade 3 or higher was found in osimertinib-treated patients than in patients treated with the gefitinib, erlotinib, and afatinib [11]. Previous literature more often discussed the overall quality of life with targeted therapy patients reporting some degree of psychological distress, but seldom discussed the details of psychological status in patients treated with EGFR-TKI therapies [9, 17]. Regarding psychological factors, few studies examine FoP, anxiety, and depression among different EGFR-TKI therapies. FoP, anxiety, and depression are common experiences for cancer patients [20, 21] and FoP is also considered as the most prevalent unmet needs (14 to 42\%) [20, 22], which will be further explored in the current study.

To our knowledge, few studies have simultaneously examined the difference in FoP, anxiety, depression between presence/absence of the AEs; as well as the differences among the three generations of EGFR-TKIs with/in consideration of both physiological and psychological factors. We hypothesized that patients with NSCLC in three generations of EGFR-TKIs (first [G1], gefitinib and erlotinib; second [G2], afatinib; third [G3], osimertinib) might be suffering from AEs causing them to have higher levels of FoP, anxiety and depression; and that patients might be experiencing different incidence rates of AEs. The results obtained in this study may indicate the need for special clinical care for the benefit of ameliorating patient health status.

\section{Methods}

\subsection{Design}

This was a prospective, comparative, cross-sectional study, and was part of a larger study on patients with NSCLC treated with EGFR-TKIs. A purposive sampling was used. For data collection, patients' AEs were assessed by the National Cancer Institute Common Toxicity Criteria and Adverse Events (CTCAE v 
4.03) and patient-reported outcome measures (PRO-CTCAE 1.0). Patients' FoP was assessed by the Fear of Progression Questionnaire-Short Form (FoP-Q-SF) [23] and anxiety and depression were assessed by the Hospital Anxiety and Depression Scale (HADS), as described in detail below

\subsection{Participants}

Patients were recruited from an oncology-dermatology outpatient setting of a medical center in Northern Taiwan from October 01, 2018 to December 12, 2019. Eligible patients (i) were $\geqq 20$ years old; (ii) had been diagnosed with NSCLC at stage IIlb or IV; (iii) had received oral EGFR-TKI treatment (gefitinib, erlotinib, afatinib, or osimertinib) for at least 2 weeks; (iv) had adverse skin-related events and were receiving treatment in an oncology-dermatology outpatient setting; and (v) were able to communicate in Mandarin or Taiwanese. All patients understood the purpose of this study and signed an informed consent form of participation. This study was approved by the Institutional Review Board of the medical center.

\subsection{Measures}

\subsubsection{Target-Adverse Events (AEs)}

AEs were assessed using the Chinese version of CTCAE v 4.03 and PRO-CTCAE 1.0. Nine CTCAE 4.03 items (acneiform eruption, pruritus, dry skin, hyperpigmentation, photosensitivity, paronychia, alopecia, hypertrichosis, and oral mucositis) [13] and six PRO-CTCAE 1.0 items (acne, itching, skin dryness, hair loss, mouth/throat sores, and cheilosis/cheilitis) were most commonly associated with target-adverse event measures [24]. The severity grade of CTCAE 4.03 was ranked as grade 1 (mild) to 5 (death) according to the descriptions of each adverse event [13]. Further, PRO-CTCAE 1.0 was used to capture the experience of the patient in respect of the AEs, and their severity (none to very severe) and frequency (never to almost constantly) were assessed [24]. The incidence rate of each adverse event with any severity grade was calculated in this study.

\subsubsection{FoP, Anxiety, and Depression}

As mentioned previously, patients' FoP was assessed using the FoP-Q-SF [23]. This scale consists of 12 items which are scored from 1 (never) to 5 (very often) and a score ranging from 12 to 60. The higher scores indicate more FoP. The cut-off point of dysfunctional level of FoP is a score of 34 or above [25]. The Cronbach's alphas of FoP-Q-SF was 0.89 in the current study.

Patients' anxiety and depression were measured by the Hospital Anxiety and Depression Scale. This scale consists of 14 items: 7 items for anxiety subscale and 7 items for depression subscale. The scores range from 0 to 21 for each subscale and higher scores reflect more anxiety and depression. The scores ranging from 0 to 7 indicate non-case and 8 to 21 indicate borderline cases or cases of anxiety or depression [26]. The Cronbach's alphas of anxiety and depression were 0.84 and 0.75 , respectively in the current study.

\subsubsection{Background Information Form}

The Background Information Form of the participants included sex, age, NSCLC stage, treatment time of targeted therapy (days), duration of outpatient treatment in dermatology (days), generation(s) of EGFR-TKIs, and Eastern Cooperative Oncology Group (ECOG) Performance Status, which was used to assess the performance status of the patients and grade them from 1 (fully active) to 5 [27].

\subsection{Statistical Analysis}

SPSS version 24.0 software was used for the data analysis. Descriptive statistics such as mean, standard deviation (SD), number, and frequency were used to describe the background information of the participants, incidence rate, and severity of the AEs, FoP, anxiety, and depression. Since the scores were not normally distributed, we used nonparametric analysis methods. Thus, the Manne-Whitney U test was used to compare the differences in FoP, anxiety, depression between presence/absence of AEs. We analyzed the differences in incidence rate of the AEs, FoP, anxiety, and depression among the three generations of EGFR-TKIs using chi-square and Fisher's exact test [28]

\section{Results}

\subsection{Subject Characteristics}

A total of 140 patients were initially approached, but 12 patients were too tired to finish the questionnaires or did not have time. Thus, data was collected from 128 patients for the final analysis (response rate $=91.4 \%$ ).

Most patients (44.5\%) had received the first-generation EGFR-TKIs (gefitinib, erlotinib; G1), and 32.8\% and 22.7\% had received the second- (afatinib; G2) and third-generation (osimertinib; G3) EGFR-TKIs, respectively. Most of the patients were female in the G1 (71.9\%) and G3 (75.9\%) groups and the percentage (50\%) of male and female was equal to the $\mathrm{G} 2$ group. The mean age was $67.6(\mathrm{SD}=10.9), 61.2(\mathrm{SD}=10.3)$, and $64.6(\mathrm{SD}=11.7)$ in the $\mathrm{G} 1, \mathrm{G} 2$, and $\mathrm{G} 3 \mathrm{groups}$, respectively. The majority of patients (92.9\% 100\%) were stage IV in three groups and the treatment time of targeted therapy (days) and ECOG performance status were similar in three groups (Table 1).

\subsection{Comparison of the Incidence Rates of the AEs}

From the perspective of the professionals, the incidence rates of photosensitivity $(p=0.0001)$, hypertrichosis $(p=0.009)$, and oral mucositis $(p=0.013)$ in the G3 group were significantly lower than those in the G1 and G2 groups. From the perspective of the patients, the incidence rates of acne $(p=0.002)$, mouth/throat sores $(p=0.004)$, and cheilosis/cheilitis $(p=0.02)$ in the $G 3$ group were significantly lower than those in the $G 2$ group (Table 2$)$. 


\subsection{The difference in FoP, anxiety, depression between presence/absence of the target- adverse events}

Patients with photosensitivity had significantly higher (worse) levels in FoP and anxiety. Patients with alopecia had significantly higher levels in anxiety. Patients with paronychia had significantly higher levels in depression (Table 3 ).

\subsection{Comparison of the Incidence Rates of FoP, Anxiety and Depression}

The incidence rates of dysfunctional FoP in the G1, G2, and G3 with borderline cases or cases were $26.3 \%, 26.3 \%$, and $13.8 \%$, respectively. The incidence rates of anxiety with borderline cases or cases in the G1, G2, and G3 were $40.4 \%, 23.8 \%$, and $24.1 \%$, respectively. Finally, the incidence rates of depression in the G1, G2, and G3 with borderline cases or cases were $42.1 \%, 16.7 \%$, and $27.6 \%$, respectively. The incidence rates of depression with borderline cases or cases $(p=$ 0.023 ) in the $\mathrm{G} 1$ group were significantly higher than those in the $\mathrm{G} 2$ groups (Table 4).

\section{Discussion}

This is the first study that has simultaneously examined the difference in levels of FoP, anxiety, depression between presence/absence of the AEs and the differences in the incidence rate of AEs and FoP, anxiety, and depression among three generations of EGFR-TKIs therapy (first, gefitinib and erlotinib [G1]; second, afatinib [G2]; third, osimertinib [G3]) in patients with NSCLC.

First, our findings are in accordance with those of previous studies [9, 17], assessments of AEs from both professionals' and patients' perspectives, as the major four AEs in our study were also acneiform eruption/acne, itching, dry skin/skin dryness, and paronychia. Further, the aforementioned studies also focused on patients treated with gefitinib, erlotinib, and afatinib. Although this study included some patients treated with osimertinib, the results were similar. From the patients' perspective, less patients (37.9\%) reported acne in the G3 group than in the G2 group in our current study but more than half of them still experienced the other three AEs, including itching, dry skin/skin dryness, and paronychia. Thus, patients should be taught how to self-care such as with the use of menthol-based anti-pruritic moisturizers and conservative nail clipping for paronychia [29]. Moreover, in a previous study, a lower incidence rate of AEs (acne, pruritus, xerosis/dry skin, and paronychia) with grade 3 or higher was found in osimertinib-treated patients $(0-1 \%)$ than in patients treated with the first and second generations of EGFR-TKIs [11]. Chu et al performed a study in Taiwan and observed that the four adverse events with grade 3 or higher was in the range $0-15 \%$ [12], similar to that in our study. Here, we observed itching (3.3\%) and dry skin (10\%) with grade 3 severity, which may result in the interruption the treatment or reduction of dosage [14]. Thus, even patients undergoing osimertinib therapy should also further discuss AEs and be advised to report adverse events to their case managers as soon as possible. In addition, our study reveals that the highest incidence rate of photosensitivity were found in patients with gefitinib, erlotinib therapy (54.4\%) and this rate was approximately 4 times higher than that of patients with osimertinib therapy (13.8\%). Thus, these results indicate that when patients are treated with gefitinib and erlotinib, the importance of using hats, protective clothing and sunblock with sun protection factor $>30$ should be conveyed in clinical settings [30,31]. Finally, our study found that AEs assessed by PRO-CTCAE 1.0 is strongly recommended for use in clinical settings, as it echoed the CTCAE v 4.03 assessment by professionals in this study. However, there were still some events such as photosensitivity that was too difficult to consider for the comparison of the severity of CTCAE. For instance, the question that was asked about photosensitivity in the PRO-CTCAE was "In the last 7 days, did you have any increased skin sensitivity to sunlight?" Therefore, we didn't include this question in this study.

From the professionals' and patients' perspectives, we found that the other major findings were gastrointestinal system-related adverse events. Higher incidence rates of mouth/throat sores, and cheilosis/cheilitis were found in patients in the G2 group and were 2 or 3 times higher than in patients in the G1 and G3 group, which a previous study only reported diarrhea symptom [18]. The incidence rate of diarrhea is reportedly higher in patients who receive afatinib therapy than in those receiving gefitinib or erlotinib therapy [18]. These results indicate that patients receiving afatinib therapy should have their diarrhea symptoms closely examined and should consider the possibility of dehydration, electrolyte imbalance, and infection [32]. Therefore, patients undergoing afatinib therapy are also recommended to have their gastrointestinal system routinely assessed at every appointment, and they should be advised to perform appropriate mouth care (4-6 times mouthwash, if necessary, increasing the frequency of the mouthwash, up to 1 hour) [32] and to drink enough water (8-10 glasses) even if they only have grade 1 diarrhea symptoms (number $<4$ times) [33].

Patients with NSCLC who received different targeted therapy suffered some skin toxicity which partly caused them to have higher levels of FoP, anxiety, depression. Similar to previous studies, the results showed that the patients' physiological and psychological indicators were simultaneously affected, and that the physiological side effects affect patients' psychological distress, body image or daily life function [9, 15, 16]. Patients experienced FoP, anxiety, depression during cancer treatment, which echoes to past studies [34,35]. In the current study, the incidence rates of anxiety in the G1 group with borderline cases or cases were over $40.4 \%$, while the rate of depression was $42.1 \%$. These findings were lower than those in a previous study [36], showing that $43.5 \%$ and $57.1 \%$ of lung cancer patients were identified with anxiety and depression [36]. This difference may be due to the fact that most patients (72.1\%) received chemotherapy whereas $13 \%$ received targeted therapy [36], which has been documented to be better tolerated than chemotherapy [37]. In addition, in our study, we also found that patients' anxiety, depression and FoP in G2 and G3 group were in the range from 13.8 to $27.6 \%$. The lower incidence rate might be supported by previous studies showing that the incidence rate of psychological distress may decrease after diagnosis or cancer treatment and then become stable $[34,35]$. Forty-five percent of patients in the $\mathrm{G} 2$ group and $96.5 \%$ of patients in the G3 group were not considered for first-line treatment. In other words, more patients might have undergone previous anti-cancer therapies suggesting that their FoP, anxiety, and depression might have decreased after initial cancer treatment and explaining why more patients experienced severe anxiety and depression in the G1 group. $61.4 \%$ of those in the G1 group were used for first-line treatment in this study. Furthermore, another reason might be that female patients are more prone to report anxiety and depression [38, 39]. 70\% of the patients in the G1 group were female. This suggests that patients have some similar degree of FoP, anxiety, depression while receiving different targeted 
therapies, even though patients had lower severity of some adverse events. Thus, in clinical settings, this psychological issue should not be overlooked. Patients should be routinely assessed and if necessary, anxiety and depression borderline cases or cases, and dysfunctional FoP cases should be referred to further care.

\section{Conclusions}

The major findings suggest that patients receiving osimertinib therapy may have lower frequency or severity of acneiform eruption/acne, photosensitivity, hypertrichosis, mouth/throat sores, and cheilosis. However, patients still reported itching, dry skin, and grade 3 severity; therefore, these events should be addressed. Furthermore, patients undergoing afatinib therapy should not ignore gastrointestinal system assessment, as these are manageable adverse events to improve their quality of life. Finally, persistent FoP, anxiety and depression in patients with targeted therapy should not be ignored and needs to be further explored.

\section{Study Limitations}

Since this was a cross-sectional data analysis, there was limited understanding of the time-related changes in the AEs, FoP, anxiety and depression in patients with NSCLC receiving EGFR-TKIs. Even though our study included PRO-CTCAE 1.0 to consider the perspective of patients, qualitative research is required for making further recommendations.

\section{Clinical Implication}

Our results suggest that health care professionals should address the priorities of care among three generations of EGFR-TKIs in patients with NSCLC. The screening results of FoP, anxiety and depression calls for routine screening and further care.

\section{Declarations}

\section{Funding}

This study was supported by grant from National Taiwan University Hospital (NTUH 108-N4171).

\section{Conflict of Interest}

The authors declare that they have no conflict of interest.

\section{Availability of data and material}

The data that support the findings of this study are available from the corresponding author upon reasonable request.

\section{Code availability:}

N/A

\section{Authors' contributions}

Y. H. Lee and C. C. Yu designed and directed the project; C. C. Yu and J. C. Chan collected the data; Y. H. Lee and C. C. Yu analysed final data; C. Y. Chu and Y. H. Lai were involved in planning and supervised the work; $Y$. $H$. Lee drafted the manuscript and $Y$. J. Chen and $H$. T. Hsu contributed to designed the tables. All authors discussed the results and commented on the manuscript.

\section{Ethics approval}

Institutional Review Board approval of National Taiwan University Hospital, Taipei, Taiwan (20180705RINB)

\section{Consent to participate}

For the research involving human subjects, freely-given, informed consent to participate in the study must be obtained from participants 


\section{Consent for publication}

N/A

\section{Conflict of Intrest}

None to declare.

\section{References}

1. Ministry of Health and Welfare. Cancer registry annual report in Taiwan. 2020; Available from: https://www.hpa.gov.tw/Pages/Detail.aspx? nodeid $=269$ \& pid $=8084$

2. Hirsch FR, Bunn PA Jr (2009) EGFR testing in lung cancer is ready for prime time. Lancet Oncol 10(5):432-433

3. Hsu JC et al., Lung cancer survival and mortality in Taiwan following the initial launch of targeted therapies: an interrupted time series study. BMJ Open, 2020. 10(5)

4. Yu HA et al (2013) Analysis of tumor specimens at the time of acquired resistance to EGFR-TKI therapy in 155 patients with EGFR-mutant lung cancers. Clin Cancer Res 19(8):2240-2247

5. Kelly WJ, Shah NJ, Subramaniam DS (2018) Management of Brain Metastases in Epidermal Growth Factor Receptor Mutant Non-Small-Cell Lung Cancer. Front Oncol 8:208

6. Kuo CN et al (2020) Cancers in Taiwan: Practical insight from epidemiology, treatments, biomarkers, and cost. J Formos Med Assoc 119(12):1731-1741

7. Le T, Gerber DE, Newer-Generation EGFR Inhibitors in Lung Cancer: How Are They Best Used? Cancers (Basel), 2019. 11(3)

8. Annunziata MC et al (2019) Retrospective Analysis of Skin Toxicity in Patients under Anti-EGFR Tyrosine Kinase Inhibitors: Our Experience in Lung Cancer. Open Access Maced J Med Sci 7(6):973-977

9. Chan JC et al (2019) A Correlational Study of Skin Toxicity and Quality of Life in Patients With Advanced Lung Cancer Receiving Targeted Therapy. J Nurs Res 27(6):e51

10. Tischer B et al (2018) A survey of patient and physician acceptance of skin toxicities from anti-epidermal growth factor receptor therapies. Support Care Cancer 26(4):1169-1179

11. Soria JC et al (2018) Osimertinib in Untreated EGFR-Mutated Advanced Non-Small-Cell Lung Cancer. N Engl J Med 378(2):113-125

12. Chu CY et al (2018) Osimertinib: A Novel Dermatologic Adverse Event Profile in Patients with Lung Cancer. Oncologist 23(8):891-899

13. National Cancer Institute. Common Terminology Criteria for Adverse Events (CTCAE) Version 4.03. 2010; Available from: https://evs.nci.nih.gov/ftp1/CTCAE/About.html

14. Tischer B et al (2017) Dermatologic events from EGFR inhibitors: the issue of the missing patient voice. Support Care Cancer 25(2):651-660

15. Lenz ER et al (1997) The middle-range theory of unpleasant symptoms: an update. ANS Adv Nurs Sci 19(3):14-27

16. Yagasaki K et al (2018) Targeted Therapy-induced Facial Skin Toxicities: Impact on Quality of Life in Cancer Patients. Asia Pac J Oncol Nurs 5(2):172177

17. Chen KL et al (2016) Comparison of Skin Toxic Effects Associated With Gefitinib, Erlotinib, or Afatinib Treatment for Non-Small Cell Lung Cancer. JAMA Dermatol 152(3):340-342

18. Pessi MA et al (2014) Targeted therapy-induced diarrhea: A review of the literature. Crit Rev Oncol Hematol 90(2):165-179

19. Wacker B et al (2007) Correlation between development of rash and efficacy in patients treated with the epidermal growth factor receptor tyrosine kinase inhibitor erlotinib in two large phase III studies. Clin Cancer Res 13(13):3913-3921

20. Armes $\mathrm{J}$ et al (2009) Patients' supportive care needs beyond the end of cancer treatment: a prospective, longitudinal survey. J Clin Oncol 27(36):61726179

21. Sun $\mathrm{H}$ et al (2019) Fear of cancer recurrence, anxiety and depressive symptoms in adolescent and young adult cancer patients. Neuropsychiatr Dis Treat 15:857-865

22. Lisy K et al (2019) Identifying the most prevalent unmet needs of cancer survivors in Australia: A systematic review. Asia Pac J Clin Oncol 15(5):e68-e78

23. Herschbach P et al (2005) Fear of progression in chronic diseases: psychometric properties of the Fear of Progression Questionnaire. J Psychosom Res 58(6):505-511

24. National Cancer Institute. Patient-Reported Outcomes version of the Common Terminology Criteria for Adverse Events (PRO-CTCAE ${ }^{T M}$ ). 2018; Available from: https://healthcaredelivery.cancer.gov/pro-ctcae/overview.html

25. Herschbach P et al (2010) Group psychotherapy of dysfunctional fear of progression in patients with chronic arthritis or cancer. Psychother Psychosom 79(1):31-38

26. Zigmond AS, Snaith RP (1983) The hospital anxiety and depression scale. Acta Psychiatr Scand 67(6):361-370

27. Oken MM et al (1982) Toxicity and response criteria of the Eastern Cooperative Oncology Group. Am J Clin Oncol 5(6):649-655

28. Evelyn Malone H, Coyne I (2019) Decision-tables for choosing commonly applied inferential statistical tests in comparative and correlation studies. Nurse Res 27(4):29-35 
29. Barton-Burke M et al (2017) Dermatologic Reactions to Targeted Therapy: A Focus on Epidermal Growth Factor Receptor Inhibitors and Nursing Care. Nurs Clin North Am 52(1):83-113

30. American Cancer Society. Targetd therapy side effects (2021) [cited 2021 Feb. 1]; Available from: https://www.cancer.org/treatment/treatments-and-sideeffects/treatment-types/targeted-therapy/side-effects.html

31. Guggina LM, Choi AW, Choi JN (2017) EGFR Inhibitors and Cutaneous Complications: A Practical Approach to Management. Oncology Therapy 5:135148

32. Carrozzo M et al., Oral Mucosal Injury Caused by Targeted Cancer Therapies. J Natl Cancer Inst Monogr, 2019. 2019(53)

33. Hirsh V et al (2014) Management of diarrhea induced by epidermal growth factor receptor tyrosine kinase inhibitors. Curr Oncol 21(6):329-336

34. Niedzwiedz CL et al (2019) Depression and anxiety among people living with and beyond cancer: a growing clinical and research priority. BMC Cancer 19(1):943

35. Savard J, Ivers H (2013) The evolution of fear of cancer recurrence during the cancer care trajectory and its relationship with cancer characteristics. J Psychosom Res 74(4):354-360

36. Yan X et al (2019) Prevalence and risk factors of anxiety and depression in Chinese patients with lung cancer: a cross-sectional study. Cancer Manag Res 11:4347-4356

37. Gerber DE (2008) Targeted therapies: a new generation of cancer treatments. Am Fam Physician 77(3):311-319

38. Abate KH (2013) Gender disparity in prevalence of depression among patient population: a systematic review. Ethiop J Health Sci 23(3):283-288

39. Inhestern L et al (2017) Anxiety and depression in working-age cancer survivors: a register-based study. BMC Cancer 17(1):347

\section{Tables}

Table 1 Patients background information $(\mathrm{N}=128)$

$\begin{array}{cccc} & \mathrm{G}^{\mathrm{a}} & \mathrm{G}^{\mathrm{b}} & \mathrm{G3}^{\mathrm{c}} \\ \text { Variables } & (\mathrm{n}=57 / 128 ; 44.5 \%) & (\mathrm{n}=42 / 128 ; 32.8 \%) & (\mathrm{n}=29 / 128 ; 22.7 \%)\end{array}$

Gender

\begin{tabular}{cccc} 
Male & $16(28.1)$ & $21(50.0)$ & $7(24.1)$ \\
\hline Female & $41(71.9)$ & $21(50.0)$ & $22(75.9)$ \\
\hline Age (years) & $67.6(10.9)$ & $61.2(10.3)$ & $64.6(11.7)$
\end{tabular}

Stage

\begin{tabular}{lccc}
\hline III & $3(5.3)$ & $3(7.1)$ & $0(0.0)$ \\
\hline IV & $54(94.7)$ & $39(92.9)$ & $29(100.0)$ \\
\hline Treatment time of targeted therapy (days) & $452.7(610.9)$ & $404.1(412.5)$ & $428.7(393.6)$ \\
\hline $\begin{array}{l}\text { Previous treatment } \\
\text { Yes }\end{array}$ & $50(38.6)$ & $19(45.2)$ & $1(3.4)$ \\
No & $35(61.4)$ & $23(54.8)$ & $28(96.6)$ \\
\hline ECOG Performance Status & $1.3(0.5)$ & $1.1(0.4)$ & $1.3(0.7)$ \\
\hline
\end{tabular}

Note凹G1 a: indicates the first-generation EGFR-TKIs (Gefitinib or Erlotinib); G2 ${ }^{\mathrm{b}}$ : indicates the second-generation EGFR-TKIs (Afatinib); G3c: indicates the third generation EGFR-TKIs (Osimertinib).

Note $G 1^{\text {a }}$ : indicates the first generation EGFR-TKIs ( Gefitinib or Erlotinib); G2 ${ }^{\mathrm{b}}$ : indicates the second generation EGFR-TKIs (Afatinib); G3c: indicates the third generation EGFR-TKIs (Osimertinib); chi-square and Fisher's exact test, " $p<0.05 \square " p<0.01 \square+0$ Bonferroni's method

Table 3 The difference in FoP, anxiety, depression between presence/absence of the target-adverse events 
Table 2 Comparison of the incidence rate of the target-adverse events assessed by CTCAE 4.03 and PRO-CTCAE 1.0

\begin{tabular}{|c|c|c|c|c|c|c|c|c|c|c|c|c|c|c|c|}
\hline & & (Pro & $\begin{array}{r}\text { CTCA } \\
\text { ssionals }\end{array}$ & $\begin{array}{l}\text { E } 4.03 \\
\text { s' persp }^{\prime}\end{array}$ & tive) & & & & & & & & $\begin{array}{l}\text { PRO-CTC } \\
\text { atients' pe }\end{array}$ & $\begin{array}{l}\text { CAE } 1.0 \\
\text { rrspective }\end{array}$ & \\
\hline \multirow{3}{*}{ Adverse Event } & \multirow{2}{*}{\multicolumn{2}{|c|}{$\begin{array}{c}\begin{array}{c}\mathrm{G} 1^{\mathrm{a}} \\
(\mathrm{n}=57)\end{array} \\
\mathrm{n}(\%)\end{array}$}} & \multirow{2}{*}{\multicolumn{2}{|c|}{$\begin{array}{c}\mathrm{G}^{\mathrm{b}} \\
(\mathrm{n}=42) \\
\mathrm{n}(\%)\end{array}$}} & \multirow{2}{*}{\multicolumn{2}{|c|}{$\begin{array}{c}\begin{array}{c}\mathrm{G}^{\mathrm{c}} \\
(\mathrm{n}=29)\end{array} \\
\mathrm{n}(\%)\end{array}$}} & \multirow{3}{*}{$\chi^{2}$} & \multirow{3}{*}{$\mathrm{p}$} & \multirow{3}{*}{ †Post hoc } & \multirow{3}{*}{ Adverse Event } & \multirow{2}{*}{\multicolumn{2}{|c|}{$\begin{array}{c}\begin{array}{c}\mathrm{G1}^{\mathrm{a}} \\
(\mathrm{n}=57)\end{array} \\
\mathrm{n}(\%)\end{array}$}} & \multirow{2}{*}{\multicolumn{2}{|c|}{$\begin{array}{c}\begin{array}{c}\mathrm{G} 2^{\mathrm{b}} \\
(\mathrm{n}=42)\end{array} \\
\mathrm{n}(\%)\end{array}$}} & \multirow{3}{*}{$\frac{\text { (n }}{\mathrm{n}}$} \\
\hline & & & & & & & & & & & & & & & \\
\hline & $\begin{array}{c}\text { All } \\
\text { Grade }\end{array}$ & $\underset{3}{\text { Grade }}$ & $\begin{array}{l}\text { All } \\
\text { Grade }\end{array}$ & $\underset{3}{\text { Grade }}$ & $\begin{array}{c}\text { All } \\
\text { Grade }\end{array}$ & $\underset{3}{\text { Grade }}$ & & & & & $\begin{array}{c}\text { All } \\
\text { Response }\end{array}$ & $\begin{array}{l}\text { Very } \\
\text { Severe }\end{array}$ & $\begin{array}{c}\text { All } \\
\text { Response }\end{array}$ & $\begin{array}{l}\text { Very } \\
\text { Severe }\end{array}$ & \\
\hline \multirow{2}{*}{ Acneiform eruption } & 47 & 5 & 34 & 2 & 16 & 0 & \multirow{2}{*}{-10.74} & \multirow{2}{*}{0.082} & \multirow{2}{*}{-} & \multirow{2}{*}{ Acne } & 36 & 1 & 34 & 0 & 11 \\
\hline & $(82.5)$ & $(8.8)$ & $(81.0)$ & $(4.8)$ & $(55.2)$ & $(0)$ & & & & & $(63.2)$ & (1.8) & $(81.0)$ & $(0)$ & (37.9) \\
\hline \multirow{2}{*}{ Itching } & 51 & 8 & 40 & 4 & 24 & 1 & \multirow{2}{*}{-5.71} & \multirow{2}{*}{0.46} & \multirow{2}{*}{-} & \multirow{2}{*}{ Itching } & 51 & 3 & 40 & 1 & 21 \\
\hline & (89.5) & (14.0) & $(95.2)$ & (9.5) & $(82.2)$ & $(3.4)$ & & & & & (89.5) & (5.3) & $(95.2)$ & $(2.4)$ & (72.4) \\
\hline \multirow{2}{*}{ Dry skin } & 51 & 4 & 37 & 3 & 22 & 3 & \multirow{2}{*}{4.02} & \multirow{2}{*}{0.68} & \multirow{2}{*}{-} & \multirow{2}{*}{ Skin dryness } & 52 & 2 & 35 & 0 & 23 \\
\hline & (89.5) & $(7.0)$ & $(88.1)$ & (7.1) & $(75.9)$ & (10.3) & & & & & $(91.2)$ & (3.5) & (83.3) & $(0)$ & (79.3) \\
\hline \multirow{2}{*}{ Hyperpigmentation } & 35 & \multirow{2}{*}{-} & 27 & \multirow{2}{*}{ - } & 13 & - & 2.94 & 0.58 & - & & & & & & \\
\hline & (61.4) & & (64.3) & & $(44.8)$ & & & & & & & & & & \\
\hline Photosensitivity & 31 & 0 & 12 & 0 & 4 & & 20.35 & $0.0001^{* *}$ & $\mathrm{G} 3<\mathrm{G} 2<\mathrm{G} 1$ & & & & & & \\
\hline 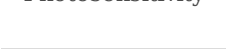 & $(54.4)$ & $(0)$ & $(28.6)$ & $(0)$ & (13.8) & (0) & & & & & & & & & \\
\hline Parnnuchia & 36 & 2 & 36 & 2 & 22 & 0 & 2125 & $0001 * *$ & $C_{1}-C_{2}$ & & & & & & \\
\hline 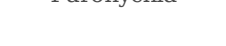 & $(63.2)$ & (3.5) & (85.7) & $(4.8)$ & (75.9) & $(0)$ & & & & & & & & & \\
\hline Alonecia & 23 & - & 14 & - & 5 & - & 708 & 011 & - & Hair loss & 21 & 0 & 16 & 0 & 5 \\
\hline - & $(40.4)$ & & (33.4) & & $(17.2)$ & & & & & (1) & $(36.8)$ & (0) & (38.1) & $(0)$ & (17.2) \\
\hline Hypertrichosis & 41 & - & 33 & - & 13 & - & 11.78 & $0.009^{* *}$ & $\mathrm{G} 3<\mathrm{G} 2$ & & & & & & \\
\hline & (71.9) & & (78.6) & & $(44.8)$ & & & & & & & & & & \\
\hline Oral mucositis & 15 & 1 & 23 & 0 & 6 & 0 & 1336 & $0013^{*}$ & $G 13<G 2$ & Mouth/throat & 10 & 0 & 18 & 0 & 5 \\
\hline - & (26.3) & $(1.8)$ & $(54.8)$ & $(0)$ & (20.7) & $(0)$ & 10.00 & & (2) & & (17.5) & (0) & $(42.9)$ & $(0)$ & (17.2) \\
\hline & & & & & & & & & & Cheilosis/cheilitis & 14 & 0 & 18 & 0 & 5 \\
\hline & & & & & & & & & & & $(24.6)$ & (0) & $(42.9)$ & (0) & $(17.2)$ \\
\hline
\end{tabular}




\begin{tabular}{|c|c|c|c|c|c|c|c|c|c|c|}
\hline & & & FoP & & & Anxiety & & & epression & \\
\hline CTCAF 403 & $\mathrm{n}$ & Mean (SD) & Mean Rank & $\mathrm{p}$ & Mean (SD) & Mean Rank & $\mathrm{p}$ & Mean (SD) & Mean Rank & $\mathrm{p}$ \\
\hline $\begin{array}{l}\text { Acneiform eruption } \\
\text { No } \\
\text { Yes }\end{array}$ & $\begin{array}{l}31 \\
97\end{array}$ & $\begin{array}{l}27.2(9.7) \\
28.0(9.3)\end{array}$ & $\begin{array}{l}61.5 \\
65.5\end{array}$ & .607 & $\begin{array}{l}4.2(3.7) \\
5.4(4.0)\end{array}$ & $\begin{array}{l}57.0 \\
66.9\end{array}$ & .192 & $\begin{array}{l}6.3(4.4) \\
5.2(3.7)\end{array}$ & $\begin{array}{l}71.3 \\
62.3\end{array}$ & .242 \\
\hline $\begin{array}{l}\text { Itching } \\
\text { No } \\
\text { Yes }\end{array}$ & $\begin{array}{c}13 \\
115\end{array}$ & $\begin{array}{l}23.5(7.2) \\
28.3(9.5)\end{array}$ & $\begin{array}{l}48.7 \\
66.3\end{array}$ & .105 & $\begin{array}{l}3.0(2.3) \\
5.3(4.1)\end{array}$ & $\begin{array}{l}46.0 \\
66.5\end{array}$ & .057 & $\begin{array}{l}5.1(4.0) \\
5.5(3.8)\end{array}$ & $\begin{array}{l}60.2 \\
65.0\end{array}$ & .655 \\
\hline $\begin{array}{c}\text { Dry skin } \\
\text { No } \\
\text { Yes }\end{array}$ & $\begin{array}{c}18 \\
110\end{array}$ & $\begin{array}{l}24.7(5.9) \\
28.3(9.7)\end{array}$ & $\begin{array}{l}52.7 \\
66.4\end{array}$ & .146 & $\begin{array}{l}4.8(3.6) \\
5.2(4.1)\end{array}$ & $\begin{array}{l}62.6 \\
64.8\end{array}$ & .809 & $\begin{array}{l}4.9(3.6) \\
5.6(3.9)\end{array}$ & $\begin{array}{l}60.1 \\
65.2\end{array}$ & .584 \\
\hline $\begin{array}{l}\text { Hyperpigmentation } \\
\text { No } \\
\text { Yes }\end{array}$ & $\begin{array}{l}53 \\
75\end{array}$ & $\begin{array}{l}26.9(9.0) \\
28.4(9.6)\end{array}$ & $\begin{array}{l}61.2 \\
66.8\end{array}$ & .402 & $\begin{array}{l}4.5(3.7) \\
5.5(4.2)\end{array}$ & $\begin{array}{l}59.4 \\
67.7\end{array}$ & .240 & $\begin{array}{l}5.5(4.2) \\
5.5(3.6)\end{array}$ & $\begin{array}{l}63.4 \\
65.3\end{array}$ & .773 \\
\hline $\begin{array}{c}\text { Photosensitivity } \\
\text { No } \\
\text { Yes }\end{array}$ & $\begin{array}{l}81 \\
47\end{array}$ & $\begin{array}{c}26.1(8.5) \\
30.8(10.0)\end{array}$ & $\begin{array}{l}58.0 \\
75.6\end{array}$ & .010 & $\begin{array}{l}4.3(3.8) \\
6.5(4.0)\end{array}$ & $\begin{array}{l}56.6 \\
78.1\end{array}$ & .001 & $\begin{array}{l}5.3(4.0) \\
5.8(3.6)\end{array}$ & $\begin{array}{l}62.3 \\
68.3\end{array}$ & .376 \\
\hline $\begin{array}{c}\text { Paronychia } \\
\text { No } \\
\text { Yes }\end{array}$ & $\begin{array}{l}34 \\
94\end{array}$ & $\begin{array}{l}27.1(8.1) \\
28.1(9.8)\end{array}$ & $\begin{array}{l}62.8 \\
65.1\end{array}$ & .756 & $\begin{array}{l}4.8(3.8) \\
5.2(4.1)\end{array}$ & $\begin{array}{l}61.6 \\
65.6\end{array}$ & .591 & $\begin{array}{l}4.0(3.0) \\
6.0(4.0)\end{array}$ & $\begin{array}{l}50.6 \\
69.5\end{array}$ & .011 \\
\hline $\begin{array}{r}\text { Alopecia } \\
\text { No } \\
\text { Yes }\end{array}$ & $\begin{array}{l}86 \\
42\end{array}$ & $\begin{array}{c}26.8(8.4) \\
29.9(10.8)\end{array}$ & $\begin{array}{l}61.2 \\
71.3\end{array}$ & .147 & $\begin{array}{l}4.5(3.7) \\
6.4(4.3)\end{array}$ & $\begin{array}{l}58.6 \\
76.5\end{array}$ & .010 & $\begin{array}{l}5.1(3.8) \\
6.3(3.9)\end{array}$ & $\begin{array}{l}60.4 \\
72.4\end{array}$ & 0.91 \\
\hline $\begin{array}{l}\text { Hypertrichosis } \\
\text { No } \\
\text { Yes }\end{array}$ & $\begin{array}{l}41 \\
87\end{array}$ & $\begin{array}{l}26.2(8.2) \\
28.5(9.8)\end{array}$ & $\begin{array}{l}57.9 \\
67.6\end{array}$ & .168 & $\begin{array}{l}4.6(4.0) \\
5.3(4.0)\end{array}$ & $\begin{array}{l}59.2 \\
67.0\end{array}$ & .267 & $\begin{array}{l}4.9(3.7) \\
5.8(3.9)\end{array}$ & $\begin{array}{l}58.9 \\
67.1\end{array}$ & .243 \\
\hline $\begin{array}{c}\text { Oral mucositis } \\
\text { No } \\
\text { Yes }\end{array}$ & $\begin{array}{l}84 \\
44\end{array}$ & $\begin{array}{l}29.8(9.3) \\
29.7(9.3)\end{array}$ & $\begin{array}{l}60.6 \\
71.9\end{array}$ & .101 & $\begin{array}{l}4.8(4.1) \\
5.6(3.7)\end{array}$ & $\begin{array}{l}61.2 \\
70.7\end{array}$ & .168 & $\begin{array}{l}5.4(3.9) \\
5.6(3.7)\end{array}$ & $\begin{array}{l}63.7 \\
66.1\end{array}$ & .726 \\
\hline
\end{tabular}

Note: The Manne-Whitney U test was used to compare the differences between the two groups.

Table 4 Comparison of FoP, anxiety and depression incidence rates $(\mathrm{N}=128)$

\begin{tabular}{|c|c|c|c|c|c|c|}
\hline & $\mathrm{G1}^{\mathrm{a}}(\mathrm{n}=57)$ & $\begin{array}{c}\mathrm{G}^{\mathrm{b}} \\
(\mathrm{n}=42)\end{array}$ & $\begin{array}{c}\mathrm{G3}^{\mathrm{c}} \\
(\mathrm{n}=29)\end{array}$ & \multirow{2}{*}{$x^{2}$} & \multirow{2}{*}{$\mathrm{p}$} & \multirow[t]{2}{*}{ †Post hoc } \\
\hline Variables (theoretical scores) & n (\%) & n (\%) & n $(\%)$ & & & \\
\hline \multicolumn{7}{|l|}{ Fear of Progression (FoP) } \\
\hline Non-dysfunctional FoP (12-33) & $42(73.7)$ & $31(73.8)$ & $25(86.2)$ & 1.94 & 0.378 & \\
\hline Dysfunctional FoP (34-60) & $15(26.3)$ & $11(26.3)$ & $4(13.8)$ & & & \\
\hline \multicolumn{7}{|l|}{ Anxiety (0-21) } \\
\hline Non-cases (0-7) & $34(59.6)$ & $32(76.2)$ & $22(75.9)$ & 3.96 & 0.138 & \\
\hline Borderline cases or cases $(8-21)$ & $23(40.4)$ & $10(23.8)$ & $7(24.1)$ & & & \\
\hline \multicolumn{7}{|l|}{ Depression (0-21) } \\
\hline Non-cases (0-7) & $33(57.9)$ & $35(83.3)$ & $21(72.4)$ & 7.53 & $0.023^{*}$ & \multirow[t]{2}{*}{$\mathrm{G} 2<\mathrm{G} 1$} \\
\hline Borderline cases or cases (8-21) & $24(42.1)$ & $7(16.7)$ & $8(27.6)$ & & & \\
\hline
\end{tabular}

Note@FoP was measured by (FoP-Q-SF); Anxiety and depression were measured by HADS; G1 ${ }^{\mathrm{a}}$ : indicates the first generation EGFR-TKIs ( Gefitinib or Erlotinib); G2 ${ }^{\mathrm{b}}$ : indicates the second generation EGFR-TKIs (Afatinib); G3c: indicates the third generation EGFR-TKIs (Osimertinib); chi-square and Fisher's exact test, "p<0.05ロ"p<0.01 †BBonferroni's method 